\title{
Taurine supplement in early life altered islet morphology, decreased insulitis and delayed the onset of diabetes in non-obese diabetic mice
}

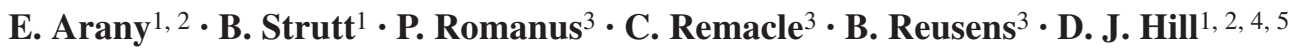 \\ ${ }^{1}$ Lawson Health Research Institute, St. Joseph's Health Care, London, Ontario, Canada \\ 2 Department of Medicine, University of Western Ontario, London, Ontario, Canada \\ ${ }^{3}$ Laboratory of Cellular Biology, World Health Collaborating Center for the Development of the Endocrine Pancreas, \\ Université Catholique de Louvain, Louvain-la-Neuve, Belgium \\ ${ }^{4}$ Department of Physiology, University of Western Ontario, London, Ontario, Canada \\ ${ }^{5}$ Department of Paediatrics, University of Western Ontario, London, Ontario, Canada
}

\section{Abstract}

Aims/hypothesis. We hypothesised that nutritional taurine, which is important for the development of the endocrine pancreas and reduces cytokine-induced apoptosis in pancreatic beta cells, would prevent or delay the onset of autoimmune diabetes, if given early in life to the non-obese diabetic (NOD) mouse.

Methods. Pregnant NOD mice received a diet supplemented with taurine throughout gestation or until weaning, and the pancreas of the offspring was examined using immunohistochemistry. This was done at postnatal day 14 and after 8 weeks (assessment of insulitis). The animals were also monitored until they became diabetic. Results. At 14 days, pancreatic islet mass was significantly greater in animals treated with taurine than in controls. This finding was associated with a greater incidence of islet cell proliferation and a lower incidence of apoptosis. At age 8 weeks the number of islets manifesting insulitis was reduced by more than half, and the area of insulitis was reduced by $90 \%$. Taurine treatment delayed the mean onset time of diabetes from 18 to 30 weeks in females, and from 30 to 38 weeks in males, while $20 \%$ of treated females remained free of diabetes after one year.

Conclusions/interpretation. Taurine supplementation in early life altered islet development, reduced insulitis and delayed the onset of diabetes in NOD mice.

Keywords Beta cell - Diabetes · IGF-II - Insulitis · Islet · NOD mouse · Taurine

\section{Introduction}

In the development of autoimmune diabetes the NOD mouse shares several immunopathogenic features with human Type 1 diabetes [1, 2]. In both, infiltration of the pancreatic islets by mononuclear leucocytes or insulitis precedes the selective destruction of islet beta

Received: 12 January 2004 / Accepted: 12 July 2004

Published online: 21 October 2004

C Springer-Verlag 2004

\section{J. Hill (®)}

Lawson Health Research Institute, St. Joseph's Health Care,

London, Ontario N6A 4V2, Canada

E-mail: dhill@1ri.sjhc.london.on.ca

Tel.: +1-519-6466100 ext 64716, Fax: +1-519-6466110

Abbreviations: NO, nitric oxide $\cdot$ NOD, non-obese diabetic · PCNA, proliferating cell nuclear antigen cells [3]. In NOD mice, diabetes is preceded by the progressive invasion of the pancreatic islets by CD4 and CD8 T cells and macrophages over a prolonged pre-diabetic period [4], with a discrepancy between the onset of insulitis and diabetes. We previously noted an altered developmental morphology in the endocrine pancreas of the diabetes-prone, female NOD mouse in early life and prior to the process of insulitis [5], suggesting that this might be a pre-disposing feature for diabetes. We therefore sought to alter pancreatic islet development in early life to increase beta cell mass using the amino acid taurine, which has been shown to have mitogenic and anti-apoptotic actions on beta cells, and through this determine if this delayed the onset of diabetes.

Taurine is a non-essential, sulfated amino acid generated from the precursors methionine and cysteine, and is a normal constituent of the diet $[6,7]$. It is present in almost all mammalian tissues but is concentrat- 
ed in certain tissues including the brain, pro-inflammatory cells and pancreas $[8,9]$. Taurine is necessary for normal development, and defects in growth, tissue differentiation and immune development occur when taurine is deficient $[10,11]$. The cellular actions of taurine are numerous, including the regulation of cell volume, extracellular and intracellular calcium mobilisation, and an inhibition of apoptosis in hepatocytes, endothelial cells and macrophages [6, 12, 13, 14, 15]. Taurine has trophic effects in the developing endocrine pancreas. When deficient, as seen during maternal protein restriction [16], taurine supplementation prevents a reduction in beta cell mass via enhanced beta cell proliferation, IGF-II expression and islet vascularisation, and by reducing islet cell apoptosis [17, $18,19]$. In addition, taurine added to the culture medium or to maternal low-protein diet prevented IL-1 and nitric oxide (NO)-induced apoptosis in isolated fetal islets while restoring insulin secretion [20, 21]. Lowprotein diet in early life resulted in a long-term susceptibility of beta cells to cytokine-induced apoptosis in adult life, and this was reversed by diet supplementation with taurine [22].

The combination of developmental actions in the endocrine pancreas and the ability to suppress cytotoxic cytokine release from mononuclear cells make taurine a potential candidate for delaying or preventing the onset of Type 1 diabetes. The aim of this study was to determine if nutritional taurine supplementation to the NOD mouse in early life could alter the morphology of the developing endocrine pancreas, change the degree of insulitis in later life, and delay the onset of diabetes.

\section{Materials and methods}

Animals and treatments. Virgin NOD females of 4 to 5 weeks and male mice were obtained from the breeding colony at the Robarts Research Institute, London, Ontario, Canada and were allowed free access to food and water. All procedures were performed with ethical approval of the Animal Care Committee of the University of Western Ontario in accordance with the guidelines published by the Canadian Council on Animal Care. At 8 weeks of age breeding pairs were caged in individual cages and females were checked daily for vaginal plugs. When pregnancy was confirmed, $2.5 \%(\mathrm{w} / \mathrm{v})$ of taurine was added to their drinking water until parturition or continued until weaning. The animals received normal Purina rat chow, and were housed in the Animal Care Facility at the Lawson Health Research Institute and maintained at $25^{\circ} \mathrm{C}$ with a $12-\mathrm{h}$ light/dark cycle. Pups were separated by sex at weaning, and killed either 14 days after birth or, in a second group, at 8 weeks of age by $\mathrm{CO}_{2}$ asphyxiation after an overnight fast. Pancreata were collected, weighed and fixed with $10 \%$ formalin in PBS for histology. Before death, blood was also collected from the tail vein at these times points, and blood glucose measured using $2 \mu \mathrm{l}$ of total blood with a fast-take glucometer (Lifescan, Burnaby, BC, Canada). A third group of mice from six to eight different litters each of taurine-treated and control animals was monitored until the onset of diabetes. The primary indicator of diabetes was polyurea on two consecutive days with a confirmation of glucosurea (6-14 mmol/l) using urine glucose strips (Diastix, Ames, Toronto, Canada). Diabetes was confirmed by a blood glucose value in excess of $11 \mathrm{mmol} / \mathrm{l}$ using blood drawn from the tail vein. Once diabetic, the animals were killed, blood glucose again recorded and the pancreas removed for histological examination.

Immunohistochemistry. Histological sections of pancreas $(5 \mu \mathrm{m})$ were cut from paraffin blocks and mounted on glass microscope slides (Superfrost Plus, fisher Scientific, Nepean, ON, Canada). Immunohistochemistry was performed on pancreas sections to localise insulin, glucagon, proliferating cell nuclear antigen (PCNA), CD3 and IGF-II within the islets by a modified avidin-biotin peroxidase method [23] using the following primary antibodies: guinea pig anti-insulin (1:50 dilution) and rabbit anti-porcine glucagon (1:100 dilution; C-terminal specific 04A antiserum) (provided by Dr T.J. McDonald, Department of Medicine, University of Western Ontario, Canada); mouse antiPCNA (1:750 dilution) (Sigma Chemical, St. Louis, Mo., USA); rat monoclonal CD3 antibody (1:100 dilution) (Santa Cruz Biotechnology, Santa Cruz, Calif., USA); and rabbit anti-IGF-II (1:200 dilution) (GroPep, Adelaide, Australia). All antisera were diluted in $0.1 \mathrm{~mol} / \mathrm{l} \mathrm{PBS}(\mathrm{pH} 7.5)$ containing $0.25 \%$ (w/v) bovine serum albumin, $0.3 \%(\mathrm{v} / \mathrm{v})$ Triton $\mathrm{X} 100$, and $0.01 \%(\mathrm{w} / \mathrm{v})$ sodium azide (100 $\mu \mathrm{l}$ per slide). Biotinylated horse anti-mouse, goat anti-rabbit and goat anti-guinea pig (1:100 dilution: Vector Laboratories, Burlingame, Calif., USA) were used as secondary antibodies. Peptide immunoreactivity was localised by incubation in fresh diaminobenzidine tetrahydrochloride (Biogenex, San Ramon, Calif., USA). Tissue sections were counter-stained with Carazzi's haematoxylin or methyl green $0.01 \%$ in acetate buffer. Controls included substitution of primary antisera with non-immune serum, the omission of the secondary antiserum, and for insulin, glucagon and IGF-II, an absence of staining following pre-incubation of the antiserum with excess antigen.

Visualisation of apoptosis. Apoptosis was visualised by the TUNEL method, with the In Situ Cell Death Detection kit (fluorescein) from Roche Diagnostics, Germany, and by using a confocal microscope (MRC-1024 UV, Bio-Rad, Hemel Hempstead, UK) with FITC (excited at $488 \mathrm{~nm}$ and emission peak at $552 \mathrm{~nm}$ ). Total nuclei were labelled with ethidium bromide (excited at $510 \mathrm{~nm}$ and emission peak at $595 \mathrm{~nm}$ ).

Morphometric and statistical analysis. Pancreata from up to 20 animals from each sex, and from at least 3 to 4 different litters were examined at each age. Morphometric analysis was performed using a Carl Zeiss transmitted light microscope at a magnification of $\times 250$ or $\times 400$. Automatic image analysis of the pancreatic sections for calculation of tissue areas was performed with Northern Eclipse, version 6.0, morphometric analysis software (Empix Imaging, Mississauga, Ontario, Canada). The number of small $\left(<5000 \mu \mathrm{m}^{2}\right)$ or large $\left(>10,000 \mu \mathrm{m}^{2}\right)$ islets, and the percent of islet cells immunoreactive for insulin, glucagon, PCNA or IGF-II, or demonstrating apoptotic nuclei, were calculated for each group from 5 sections per pancreas taken at 50 to 60 section intervals to represent the entire pancreas at 14 days of age. For islet cell apoptosis and IGF-II presence at 14 days, only female pancreata were analysed. The minimum size for an islet was taken to be a cluster of three or more insulin-positive cells. Calculation of the percent of islet cells immunopositive for PCNA was also determined at 8 weeks of age using 5 sections per pancreas representing the head region. For the estimation of insulitis $5 \times 5-\mu \mathrm{m}$ sections were cut at 10 -section intervals, stained with haematoxylin-eosin, and the area of insulitis calculated. 
Table 1. Islet characteristics in pancreata from NOD mice at 14 days of age

\begin{tabular}{llcll}
\hline Animals & $\begin{array}{l}\text { Volume-weighted mean } \\
\text { islet volume, }\left(\mu \mathrm{m}^{3} \times 10^{-5}\right)^{\mathrm{a}}\end{array}$ & Islet mass, $(\mu \mathrm{g})^{\mathrm{a}}$ & $\begin{array}{l}\text { Islet beta cell } \\
\text { area }(\%)\end{array}$ & PCNA $(\%)$ \\
\hline Female control & $7.03 \pm 1.36$ & $664 \pm 216^{* *}$ & $75 \pm 2$ & $4.47 \pm 0.86$ \\
Female taurine & $6.98 \pm 2.80$ & $885 \pm 291^{*}$ & $88 \pm 2 \dagger$ & $8.16 \pm 1.24 *$ \\
Male control & $7.46 \pm 1.30$ & $962 \pm 148$ & $78 \pm 2$ & $4.72 \pm 1.06$ \\
Male taurine & $3.40 \pm 1.06$ & $1258 \pm 339^{*}$ & $81 \pm 2$ & $6.96 \pm 0.99 *$ \\
\hline
\end{tabular}

Values are means \pm SEM. $n=15-20$ animals; ${ }^{\mathrm{a}} n=5 ; * p<0.05$ vs control; $* * p<0.01$ vs control male; $\dagger p<0.005$ vs control

Pancreatic islet cell mass and volume-weighted mean islet volumes were calculated as described by Bock et al. [24, 25]. Islet cell mass was calculated from:

$M($ islet $)=M($ tissue $) \times \frac{\text { area islet }}{\text { area islet }+ \text { area non }- \text { islet }}$

where $\mathbf{M}$ (islet) is the total islet mass and $\mathbf{M}$ (tissue) is the weight of the pancreatic tissue removed. Volume-weighted mean islet volume represents the mean volume of islets weighted proportional to their volume and is considered a more accurate estimate than a simple number-weighted mean islet volume [24]. It was calculated from:

$v_{v}=\frac{\pi}{3} \times \overline{l_{0}^{3}}$

where $\mathrm{v}_{\mathrm{v}}$ is the volume-weighted mean islet volume and $\mathrm{l}_{0}$ is the length of the line between the two intercepts of an islet and a horizontal line through a point grid that hits an islet [24].

Differences between mean values for variables within individual experiments were compared statistically by two-way analysis of variance, and were considered to be significantly different at a $p$ value of 0.05 or less. Values are given as mean values \pm SEM. Differences in the conversion of NOD mice to diabetes with and without taurine supplementation were calculated from Kaplan-Meier cumulative plots and evaluated using the Wilcoxon test for equality of survival.

\section{Results}

The offspring of NOD mice supplemented with dietary taurine during pregnancy and lactation were of similar birth size, gestational length and litter size to control-fed mice, and suckled normally. Similarly, at 8 weeks of age there were no differences in body or pancreatic weight between control and taurine-supplemented animals, when male and female animals were separately compared. Mean fasting blood glucose levels did not differ statistically between taurine-treated or control females $(5.0 \pm 0.5 \mathrm{mmol} / \mathrm{l}$ vs $4.2 \pm 0.3 \mathrm{mmol} / \mathrm{l}$, $n=12)$ or males $(4.6 \pm 0.3 \mathrm{mmol} / \mathrm{l}$ vs $4.5 \pm 0.4 \mathrm{mmol} / \mathrm{l})$ at 8 weeks age.

Pancreata were removed at postnatal day 14 to determine if taurine treatment until birth was associated with altered islet morphology or biochemistry. No insulitis was apparent in any animal, with or without taurine, at this age (Fig. 1). Calculation of islet cell mass on a sub-set of animals $(n=5)$ showed that this was significantly lower in control-fed female NOD mice than in males at postnatal day 14 , but in each sex endocrine mass was increased following exposure to

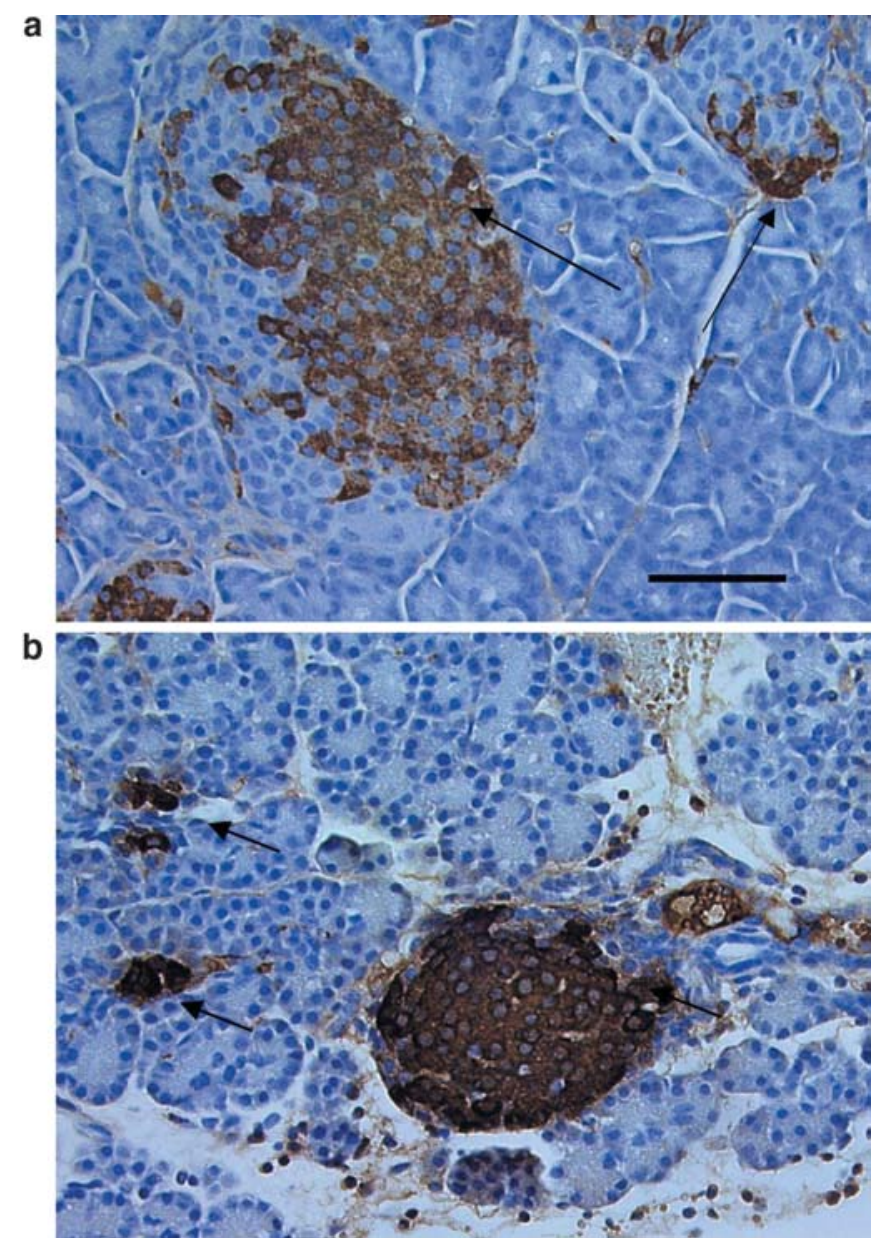

Fig. 1. Immunohistochemical localisation of insulin within islets. The arrows show islets from control (a) or taurine-supplemented (b) female NOD mice at 14 days postnatal age. The ratio of small to large islets was increased following exposure to taurine. Magnification bar $10 \mu \mathrm{m}$

taurine (Table 1). In taurine-supplemented animals volume-weighted mean islet volume did not differ between sexes or following supplementation with taurine. However, when the ratio of small islet number $\left(<5000 \mu \mathrm{m}^{2}\right.$ area $)$ to very large islet number $\left(>10,000 \mu \mathrm{m}^{2}\right)$ was calculated, this was greater in females following taurine treatment $(0.84 \pm 0.08, p<0.05)$ than in control-fed animals $(0.69 \pm 0.05)$. Since mean islet mass was increased in these animals, this probably derived predominantly from a greater number of 


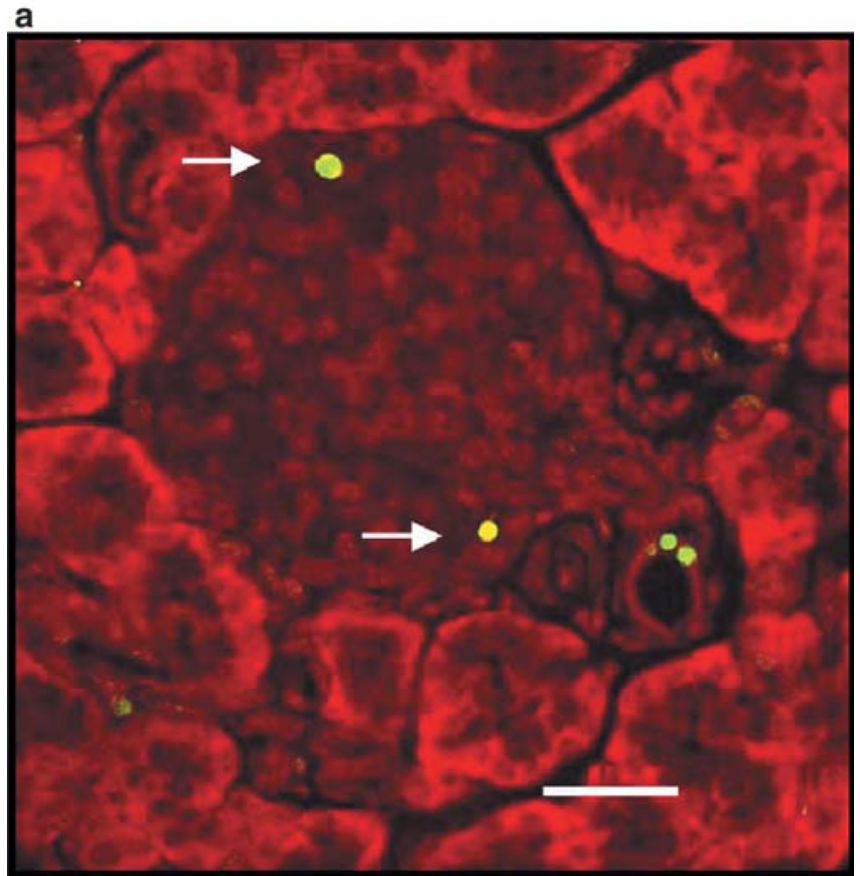

b

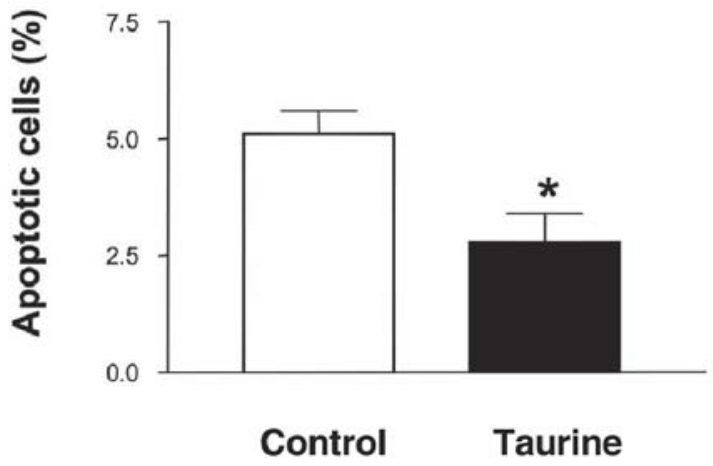

Fig. 2. a Immunofluorescent localisation of apoptosis within an islet and pancreatic duct (arrows) from a control female NOD mouse at 14 days postnatal age. Magnification bar $10 \mu \mathrm{m}$. b Percentage (mean \pm SEM) of apoptotic islet cells that were immunopositive in control (open bar) or taurine-supplemented (filled bar) animals. Values are from 15 to 20 animals for each group. ${ }^{*} p<0.01$ vs control mice

smaller sized islets. A similar trend in islet size ratio was seen in male animals following exposure to taurine, but this was not significant. Within individual islets, the proportional area occupied by insulinimmunoreactive beta cells was similar between males and females, but was significantly elevated in females treated with taurine (Table 1). The islets from taurinetreated mice had almost double the number of cells immunopositive for PCNA (Table 1), accompanied by a reduction in the incidence of apoptosis in islet cells (Fig. 2), and also a significant increase in the number of islet cells immunopositive for IGF-II (Table 1). a

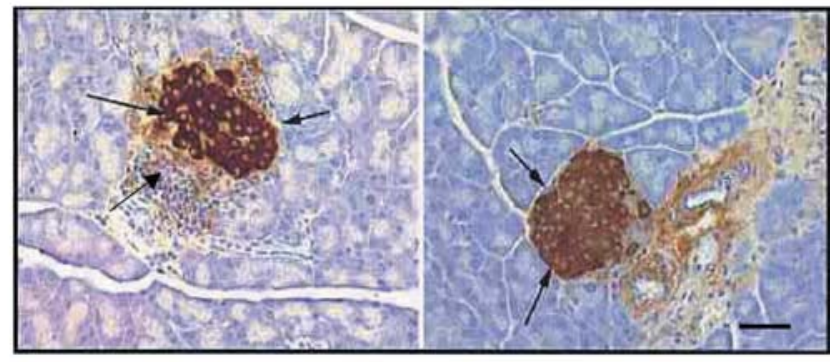

b

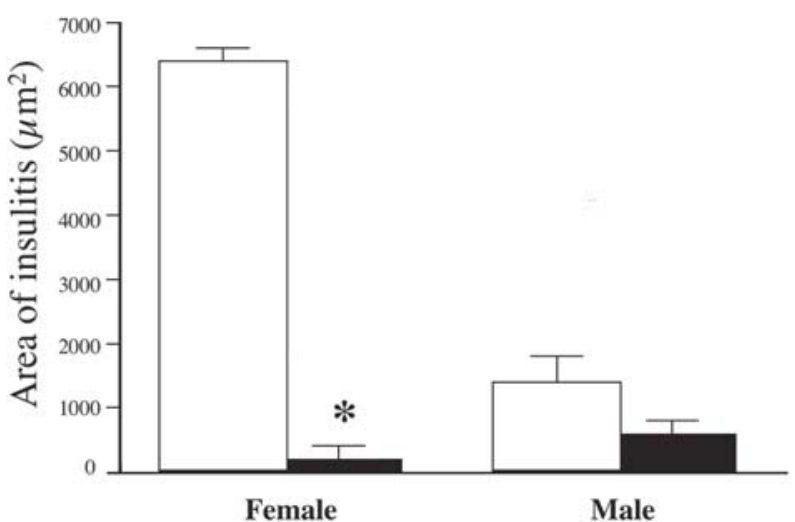

Fig. 3. a Immunohistochemical localisation of insulin within islets (arrows) from control (left) or taurine-supplemented (right) female NOD mice at 8 weeks of age. Peri-insulitis is seen in the control animal (arrow), but is absent in the taurinetreated one. Magnification bar $10 \mu \mathrm{m}$. b Area of insulitis (mean \pm SEM) in female or male control (open bars) or taurine-treated (filled bars) mice. Values are from 12 animals for each group. ${ }^{*} p<0.001$ vs control mice

At 8 weeks of age sections of pancreata were examined histologically for the presence of peri- and intra-islet insulitis in animals that had received taurine supplementation until weaning. Insulitis in some form was present in association with approximately $35 \pm 8 \%$ of islets in male and $35 \pm 7 \%$ in female control mice. In taurine-supplemented animals significantly less islets showed evidence of insulitis (males $14 \pm 8 \%$, females $7 \pm 2 \% ; p<0.05$ ). In control female mice, those islets demonstrating insulitis had an extensive mean area of infiltration, this being mainly peri-islet in nature, but with occasional intra-islet infiltration visible (Fig. 3). The infiltration showed a heavy presence of CD3 immunopositive mononuclear cells (not shown). Male animals had a much lesser area of infiltration, with no intra-islet mononuclear cell presence. Female animals which had been supplemented with taurine showed a more than $90 \%$ reduction in the area of islet infiltration, with that remaining being peri-islet in nature. A smaller reduction in the area of islet infiltration was found in males. Consequently, the mean area of islets remaining free of infiltration was greater in female mice that

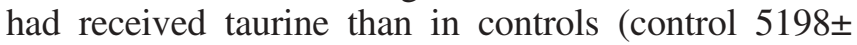


a
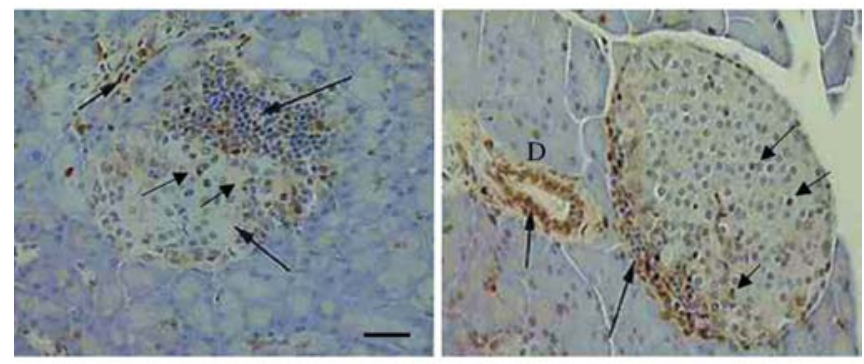

b

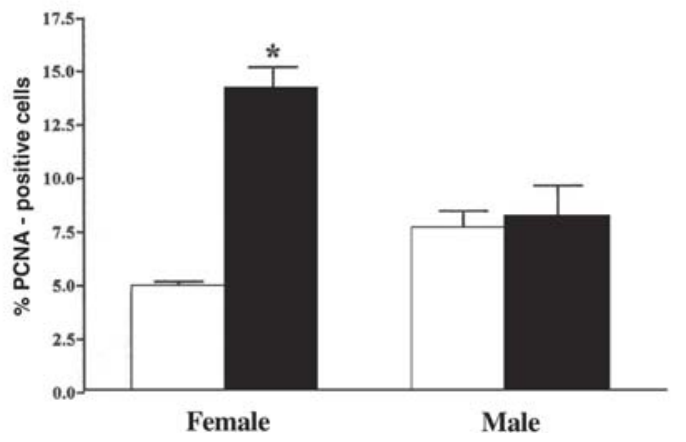

Fig. 4. a Immunohistochemical localisation of proliferating cell nuclear antigen (PCNA) within islets (arrows) from control (left) or taurine-supplemented (right) female NOD mice at 8 weeks of age. An invasive insulitis is seen in the control animal (arrow), but is absent in the taurine-treated one, which has only a mild peri-insulitis on the left. A high PCNA labelling is also seen in the epithelium of the pancreatic duct (D). Magnification bar $10 \mu \mathrm{m}$. b Percentage islet cell labelling with PCNA (mean \pm SEM) in female or male control (open bars) or taurine-treated (filled bars) mice. Values are from 12 animals for each group. ${ }^{*} p<0.001$ vs control mice

$689 \mu \mathrm{m}^{2}$, taurine $\left.9693 \pm 2415 \mu \mathrm{m}^{2}, p<0.05, n=12\right)$. However, this was also significantly greater than the mean islet size in male animals, with or without taurine, suggesting an increased proliferative activity. Consequently, islets remaining free of infiltration in females showed a significantly higher number of endocrine cells immunoreactive for PCNA following taurine administration, which was also higher than that seen in islets from males (Fig. 4). There was no change in the incidence of islet cell apoptosis in females administered taurine, and the proportional presence of beta or alpha cells was not altered, suggesting that the higher rate of DNA synthesis was not selective for beta cells. A twofold increase in the percent presence of PCNA immunopositive cells was also seen within the pancreatic duct epithelium following taurine administration to female mice (control $24 \pm 2 \%$, taurine $49 \pm 2 \%, p<0.001$, $n=12$ ) (Fig. 4a), but no changes were found in males.

Mice given taurine supplementation until weaning were monitored until the appearance of consistent a

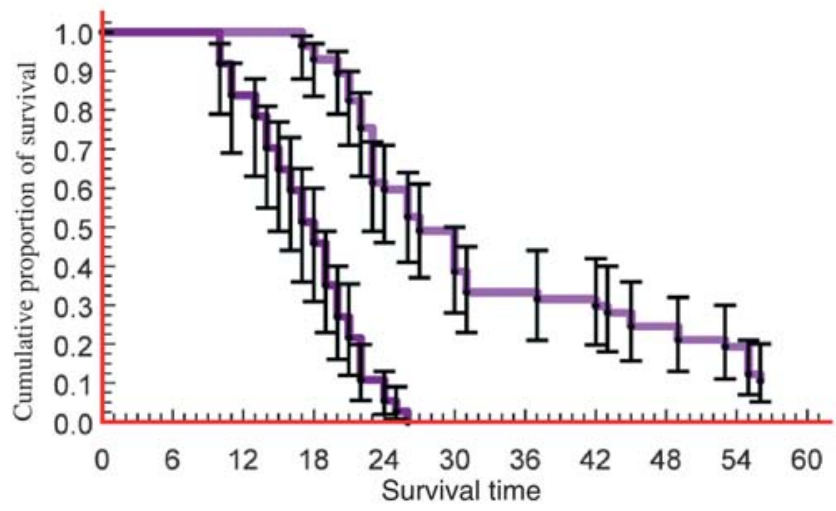

b

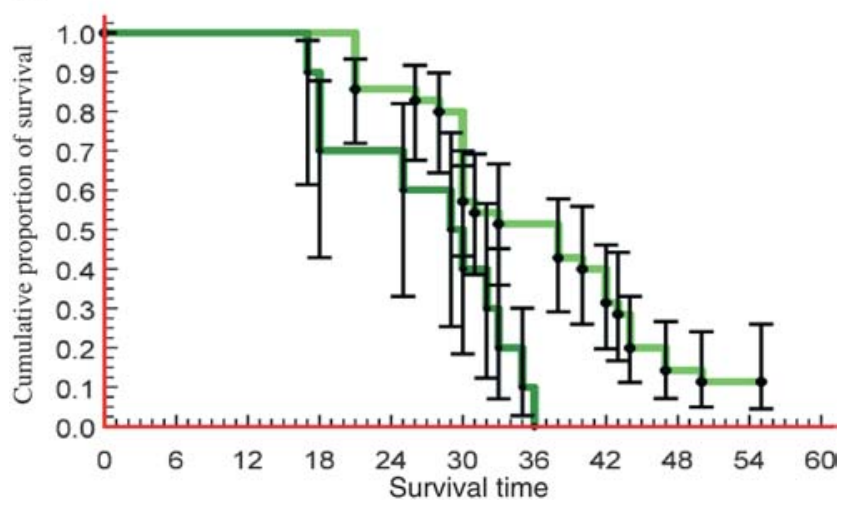

Fig. 5. Kaplan-Meier survival plots of NOD female (a) or male (b) mice without diabetes with increasing age (in weeks) for control (dark, $n=37-40$ ) or taurine-supplemented (light, $n=45-51)$ animals. $95 \%$ confidence limits are shown. $p<0.001$ for taurine-treated vs control females and $p<0.01$ for males (Wilcoxon test)

glucosurea, and diabetes was confirmed by the presence of a blood glucose level in excess of $11 \mathrm{mmol} / \mathrm{l}$ (mean 14.9 $\pm 1.1 \mathrm{mmol} / \mathrm{l}$ ). Females not supplemented with taurine had an initial age of onset of diabetes of 10 weeks, showed a $50 \%$ conversion rate by 18 weeks, and had all become diabetic by 26 weeks of age (Fig. 5a). However, animals supplemented with taurine had a delayed onset at 18 weeks, a 50\% incidence of conversion at 30 weeks, while $20 \%$ of animals were still normoglycaemic after a year. The survival time was significantly increased. When the pancreata of such animals were examined, peri-insulitis was present but no intra-islet insulitis had developed. Male animals had a delayed onset of diabetes compared to females, a lower conversion rate with a $50 \%$ incidence by 30 weeks, but in this colony all males did eventually become diabetic (Fig. 5b). Taurine supplementation also delayed the onset of diabetes in male mice, with around $10 \%$ still being free of diabetes after a year. 


\section{Discussion}

Exposure to taurine supplementation in utero and prior to weaning had long-lasting beneficial effects on beta cell survival in the NOD mouse model of autoimmune diabetes. It seems likely that these effects were due to an altered development of the islet cells, the peripheral immune system, or both. While it is well documented that dietary factors can either precipitate or delay the onset of diabetes in the NOD mouse, this is usually achieved with changes in complex proteins rather than an individual amino acid [26], and with treatment commencing after weaning.

Taurine supplementation in gestation resulted in a greater incidence of islet cell DNA synthesis and a greater islet cell mass in both sexes, an increased number of islet cells containing immunoreactive IGF-II, and a reduction in islet cell apoptosis in mice at 14 days after birth, and prior to any evidence of insulitis. We reported previously that taurine supplementation of the pregnant rat was able to reverse the loss of beta cell mass in the offspring caused by exposure to a low-protein diet, with a corresponding increase in islet cell proliferation, a reduction in Fas presence and rate of cell apoptosis, and increased presence of IGF-II [18]. Multiple direct cellular signalling pathways might be involved. In retinal cells taurine enhanced proliferation by invoking $\mathrm{Ca}^{2+}$ flux [13], in macrophages a prevention of apoptosis was mediated by a reduction in inducible nitric oxide synthase and NF-kappa B [14], and in hepatocytes an activation of phosphatidylinositol 3-kinase led to inhibition of Fas-mediated apoptosis [15].

An indirect trophic action of taurine via the expression of islet IGF-II is possible, as was already observed and discussed in a previous study in which the maternal low-protein diet was supplemented with taurine [18]. Changes in islet size distribution in the NOD neonatal mouse, as well as the altered trophic indicators, were more prominent in females. We previously found that NOD female mice differ in the ontogeny of the endocrine pancreas during neonatal life compared to males or control strains. The neonatal wave of developmental apoptosis within beta cells which peaks at postnatal day 11 in mice was significantly more pronounced in female NOD animals than in BALB/c controls [5]. This resulted in the female NOD having a lower mean islet size with a relative deficiency in beta cells subsequent to this developmental remodelling. Similarly, in the present study islet cell mass was significantly smaller in control females than in males at postnatal day 14 . We have postulated that the increased beta cell apoptotic activity seen in females might act as an early initiator of the autoimmune cascade [5].

Peri-insulitis is first found in the NOD female at around 4 to 5 weeks and affects 70 to $90 \%$ of islets by 9 to 10 weeks [27]. When examined at 8 weeks of age, taurine-supplemented female mice had a $90 \%$ reduction in the mean area of insulitis per islet. This suggests that the immune infiltration within the islets was impaired, which could imply that recognition of the beta cell auto-antigens by macrophages or dendritic cells was reduced, leading to diminished $\mathrm{T}$ cell recruitment or action. Taurine is abundant in neutrophils, and taurine or taurine chloramines, which are produced during inflammation by reaction of hypochlorous acid with taurine, reduce inflammation and the number of inflammatory cells [28, 29]. Despite discontinuation of taurine supplementation at three weeks of age, insulitis was reduced at 8 weeks, suggesting that the metabolic consequences of increased taurine availability were prolonged, and/or that the phenotypes of either the beta cells or sentinel macrophages/dendritic cells within islets had been changed. At 8 weeks of age taurine-supplemented female mice also demonstrated an increase in the number of islet cells undergoing DNA synthesis, which might indicate an attempt at regeneration to maintain beta cell mass. Since an increased incidence of DNA synthesis was also seen in the pancreatic ductal epithelium, such a regenerative response might also involve neogenesis of new endocrine cells from ductal precursors. No increase in the incidence of islet cell DNA synthesis was seen in male NOD mice previously supplemented with taurine at 8 weeks of age. Since the onset of diabetes is relatively delayed in males, this may reflect a lower beta cell loss and smaller requirement for a regenerative response.

The onset of diabetes in the female NOD mouse occurs at 11 to 15 weeks in most colonies (range 4-25 weeks), with a mean incidence of conversion of 19 weeks (range 7-37 weeks) [28]. While male mice develop insulitis at the same time as females, the onset of diabetes is delayed (mean 14 weeks, range 6-25 weeks), and the peak incidence of conversion is 23 weeks, although all males ultimately become diabetic [27]. In this study control females first became diabetic at 10 weeks, and males at 18 weeks, which is more rapid than in many colonies, but well within the range of experience. The retardation in peak onset of diabetes caused by taurine supplementation was over 12 weeks in females and 8 weeks in males. This, together with the lack of diabetes in 1 in 5 female NOD mice after 1 year, subsequent to taurine exposure in early life, is unlikely to be explained by transient metabolic effects of taurine, and suggests a long-term change either in beta cell responsiveness to autoimmune attack or in autoimmune inter-cellular communication.

In conclusion, the findings show that taurine supplementation in fetal and neonatal life delays the onset of diabetes in the NOD mouse and is associated with an altered beta cell development prior to the onset of insulitis. 
Acknowledgements. We are grateful to the Canadian Diabetes Association, the Juvenile Diabetes Research Foundation, the Canadian Institutes of Health Research, The Stem Cell Network Centre of Excellence, the Ontario Research and Development Challenge Fund, Fond National de la Recherche Scientifique of Belgium, and the Parthenon Trust, London, UK for financial support. We thank Catherine Currie for technical support and Dr Sandra Thyssen for help in statistical analysis.

\section{References}

1. Kikutani H, Makino S (1992) The murine autoimmune diabetes model: NOD and related strains. Adv Immunol 51:285-322

2. Lampeter EF, Signore A, Gale EAM, Pozzili P (1989) Lessons from the NOD mouse for the pathogenesis and immunotherapy of human type 1 (insulin-dependent) diabetes mellitus. Diabetologia 32:703-708

3. Castano L, Eisenbarth, GS (2001) Type I diabetes: a chronic autoimmune disease of human, mouse and rat. Annu Rev Immunol 8:647-679

4. Signore A, Pozzili P, Gale EAM, Andreani D, Beverley PCL (1989) The natural history of lymphocyte subsets infiltrating the pancreas of the NOD mice. Diabetologia 32:282-289

5. Trudeau JD, Dutz JP, Arany E, Hill DJ, Fieldus WE, Finegood DT (2000) Neonatal $\beta$-cell apoptosis: A trigger for autoimmune diabetes? Diabetes 49:1-7

6. Huxtable RJ (1992) Physiological actions of taurine. Physiol Rev 72:101-163

7. Huxtable R, Fanconi F, Gironi A (1987) The biology of taurine. Methods and mechanisms. Plenum Press, New York

8. Briel G, Gylfe E, Hellman B, Neuhoff V (1972) Microdetermination of free amino acids in pancreatic islets isolated from obese-hyperglycemic mice. Acta Physiol Scand $84: 247-253$

9. Bustamente J, Lobo MVT, Alonso NTA et al. (2001) An osmotic sensitive taurine pool is located in rat pancreatic islet cells containing glucagon and somatostatin. Am J Endocr Metab 281:E1275-E1285

10. Lake N, Wright ED, Lapp WS (1992) Effect of taurine deficiency on immune function in mice. Adv Exp Med Biol 315:241-243

11. Schuller-Levis G, Mehta PD, Rudelli R, Sturman J (1990) Immunological consequences of taurine deficiency in cats. J Leucocyte Biol 47:321-331

12. Palmi M, Youmbi GT, Fusi F et al. (1999) Potentiation of mitochondrial $\mathrm{Ca} 2+$ sequestration by taurine. Biochem Pharmacol 58:1123-1131

13. Wu QD, Wang JH, Fennessy F, Redmond HP, BouchierHayes D (1999) Taurine prevents high-glucose-induced human vascular endothelial cell apoptosis. Am J Physiol 277:C1229-C1238

14. Barua M, Liu Y, Quinn MR (2001) Taurine chloramine inhibits inducible nitric oxide synthase and TNF-alpha gene expression in activated alveolar macrophages: decreased NF-kappa B activation and Ikappa B kinase activity. J Immunol 167:2275-2281
15. Takikawa Y, Miyoshi H, Rust C et al (2001) The bile acidactivated phosphatidylinositol 3-kinase pathway inhibits Fas apoptosis upstream of bid in rodent hepatocytes. Gastroenterology 120:1810-1817

16. Reusens B, Dahri S, Snoeck A et al. (1995) Long term consequences of diabetes and its complications may have a fetal origin: experimental and epidemiological evidences. In: Cowett RM (ed.) Nestlé Nutrition Workshop Series, vol 25. Raven Press, New York, pp 187-198

17. Petrik J, Reusens B, Arany E, Remacle C, Hoet JJ, Hill DJ (1999) A low protein diet alters the balance of islet cell replication and apoptosis in the fetal and neonatal rat, and is associated with a reduced pancreatic expression of insulin-like growth factor-II. Endocrinology 140:4861-4873

18. Boujendar S, Reusens B, Merezak S et al. (2002) Taurine supplementation to a low protein diet during foetal and early postnatal life restores normal proliferation and apoptosis of rat pancreatic islets. Diabetologia 45:856-866

19. Boujendar S, Arany E, Hill DJ, Remacle C, Reusens B (2003) Taurine supplementation during fetal life reverses the vascular impairment caused to the endocrine pancreas by a low protein diet. J Nutr 133:2820-2825

20. Merezak S, Hardikar AA, Yajnik CS, Remacle C, Reusens B (2001) Intrauterine low protein diet increases fetal $\beta$ cell sensitivity to NO and IL-1 $\beta$ : the protective role of taurine. J Endocrinol 171:299-308

21. Cherif H, Reusens B, Ahn MT, Hoet JJ, Reusens B (1998) Effects of taurine on the insulin secretion of rat fetal islets from dams fed a low protein diet. J Endocrinol 159:341348

22. Merezak S, Reusens B, Renard A et al. (2004) Early low protein diet increases the vulnerability of rat adult rat islet to cytokines: preventive role of taurine. Diabetologia 47:669-675

23. Hsu SM, Raine L, Fanger H (1981) Use of avidin-biotin peroxidase complex (ABC) in immunoperoxidase techniques: a comparison between $\mathrm{ABC}$ and unlabelled antibody (PAP) procedures. J Histochem Cytochem 29:577580

24. Bock T, Pakkenberg B, Buschard K (2003) Increased islet volume but unchanged islet number in ob/ob mice. Diabetes 52:1716-1722

25. Bock T, Kynel A, Pakkenberg B, Buschard K (2003) The postnatal growth of the beta-cell mass in pigs. J Endocrinol 179:245-252

26. Hoorfar J, Buschard K, Dagnaes-Hansen F (1993) Prophylactic nutritional modification of the incidence of diabetes in autoimmune non-obese diabetic (NOD) mice. Br J Nutr 69:597-607

27. Pozzilli P, Signore A, Williams AJK, Beales PE (1993) NOD mouse colonies around the world-recent facts and figures. Immunol Today 14:193-196

28. Marcinkiewicz J, Nowak B, Grabowska A, Bobek M, Petrovska L, Chain B (1999) Regulation of murine dendritic cell functions in vitro by taurine chloramine, a major product of the neutrophil myelopeoxidase-halide system. Immunology 98:371-378

29. Barua M., Liu Y, Quinn M (2001) Taurine chloramine inhibits inducible nitric oxide synthase and TNF- $\alpha$ gene expression in activated alveolar macrophages: decreased NF-kappaB activation and IkappaB kinase activity. J Immunol 167:2275-2281 